\title{
Biotin-Avidin Mediated Homogeneous Enzyme-Linked Binding Assays for Riboflavin and Riboflavin Binding Protein Using Alkaline Phosphatase as the Label ${ }^{\dagger}$
}

\author{
Hye Jin Kıм, Mi Jeoung Kıм, Jin Mog Кıм and Geun Sig CHA $† \dagger$ \\ Department of Chemistry and Research Institute of Basic Science, Kwangwoon University, \\ 447-1 Wolgye-Dong, Nowon-Ku, Seoul 139-701, Korea
}

\begin{abstract}
The feasibility of using alkaline phosphatase (ALP) as a generic label in a homogeneous type assay is examined. In the proposed ALP-based biotin-avidin mediated assay, the activity of the ALP-biotin conjugate is inhibited in the presence of the avidin-riboflavin conjugate, and the observed inhibition is reversed in an amount proportional to the concentration of riboflavin binding protein (RBP) added. The ALP activity of the mixture is re-inhibited upon additions of free analyte riboflavin, to an extent proportional to the concentration of riboflavin added to the assay mixture. An avidin-riboflavin conjugate with a desired inhibitory effect is prepared by protecting the binding-site of avidin with 2-iminobiotin during the conjugation reaction at $\mathrm{pH}$ 6.5. The catalytic activity of ALP, conjugated with biotin, is inhibited to a significant degree (up to $86 \%$ ) by the binding of the avidin-riboflavin conjugate, and is fully recovered upon additions of RBP.
\end{abstract}

Keywords Homogeneous assay, biotin-avidin interaction, alkaline phosphatase label, riboflavin, riboflavin binding protein

With the increased use of enzyme labels as alternatives to radioisotopes in the development of immunoassay methods, a number of different types of enzyme-linked binding assays have been introduced for the selective determination of biologically important molecules (for example: hormones, vitamins, and proteins). ${ }^{1-3}$ Such methods can be categorized as either heterogeneous or homogeneous. The homogeneous types such as the enzyme-multiplied immunoassay technique (EMIT), pioneered by Rubenstein et $a l_{.}{ }^{4,5}$, are much preferred because there is no need for time-consuming separation of the free and bound enzyme label. These methods rely on the ability of analyte-specific binders (e.g., antibodies or binding proteins) to inhibit or activate the activity of enzyme-analyte conjugates in solution. In most cases, the catalytic activity of the conjugated enzyme is decreased, owing to steric effects or conformational changes induced by the binding of the binders to the enzyme-analyte conjugates. When free analyte molecules (from the sample) are present, competition for a limited number of binding sites causes an increase in enzyme activity, and this increase is proportional to the concentration of analyte present in the assay mixture.

Very recently, we $^{6}$ reported on the use of synthetic conjugates in the development of the biotin-avidin mediated homogeneous assays by employing riboflavin

† Presented at the ASIANALYSIS III, August 20 - 24, 1995, Seoul, Korea.

it To whom correspondence should be addressed. and riboflavin binding protein (RBP) as the model analyte and anti-analyte binder system. In this method, the binding reaction between the avidin-analyte and enzyme-biotin conjugates inactivates the enzyme conjugate. In the presence of analyte-specific binder, the enzymatic activity of the conjugate is regained, since the binding of the binder to the avidin-analyte conjugate prevents the enzyme inactivation by sterically hindering the binding between the avidin-analyte and enzymebiotin conjugates. When free analyte is added to the assay mixture, activity is re-inhibited to an extent proportional to the analyte concentration.

Based on this approach, we ${ }^{6}$ demonstrated that singlesubstrate enzymes such as adenosine deaminase and alkaline phosphatase (ALP) can be used as a generic label in devising homogeneous type assays. Enzyme labels typically used in the EMIT type homogeneous assays have been two-substrate enzymes such as glucose-6phosphate dehydrogenase and malate dehydrogenase: ${ }^{1-3}$ the catalytic activity of these dehydrogenase enzymes is measured by photometric detection of NADH at $340 \mathrm{~nm}$. However, the activity of ALP, which is not typically used in homogeneous type assays ${ }^{1-3}$, can be monitored at a longer wavelength (e.g., $405 \mathrm{~nm}$ ), enabling the assay system to utilize a visual detection scheme. In addition, activity measurements at $405 \mathrm{~nm}$ rather than $340 \mathrm{~nm}$ could make it easier to adapt the homogeneous assay to a microtiter plate reader format. Many plate readers are not able to reliably monitor absorbance at $340 \mathrm{~nm}$ due to lack of the proper filter and to rather unstable 
readings, owing to background absorbance of the plate materials in this wavelength region. ${ }^{7}$ Furthermore, ALP is available commercially in pure form with specific activities as high as $2000-3000$ units/mg.

The aim of this work is to examine further the characteristics of the biotin-avidin mediated assay by employing a single-substrate enzyme, alkaline phophatase, as the label. Various avidin-riboflavin conjugates are prepared at several different $\mathrm{pHs}$ with or without active-site protection, and their binding properties are compared. The dose-response behavior (i.e., detection limit, effective detection range, and steepness) of the assay system is shown to be influenced by the ratio of the reagents (i.e., ALP-biotin, avidin-riboflavin and RBP) employed in the assay mixture.

\section{Experimental}

\section{Apparatus}

Enzymatic activities were measured with a Gilford Stassar-III spectrophotometer equipped with a vacuumoperated sampling system and temperature-controlled cuvette (maintained at $30^{\circ} \mathrm{C}$ throughout the experiments). This spectrophotometer was connected to a Syva CP-5000 EMIT Clinical Processor for automatically setting the reading intervals and recording the absorbance values.

\section{Reagents}

Alkaline phosphatase (ALP) from bovine intestinal mucosa, bovine serum albumin (BSA), $N$-hydroxysuccinimidobiotin (NHS-biotin), 2-iminobiotin, $p$-nitrophenyl phosphate, avidin from egg white, riboflavin binding protein (RBP) from chicken egg white and riboflavin, as well as all other biochemicals, were obtained from Sigma (St. Louis, MO). Activity measurements of ALP and its conjugates as well as dilutions of conjugates, binders and standards were made by using $0.05 \mathrm{M}$ sodium carbonate (pH 9.5) containing $0.1 \mathrm{M} \mathrm{NaCl}, 0.01 \%$ (w/v) $\mathrm{NaN}_{3}$, $0.01 \%$ gelatin $(\mathrm{w} / \mathrm{v})$ and $0.2 \% \mathrm{BSA}(\mathrm{w} / \mathrm{v})$ (i.e., assay buffer).

\section{Preparation of enzyme-biotin conjugates}

The ALP-biotin and avidin-riboflavin conjugates were synthesized using the $N$-hydroxysuccinimide ester method, as described previously. ${ }^{6}$ Briefly, the required amount of NHS-biotin dissolved in DMF $(5-50 \mathrm{mg} / \mathrm{ml})$ was added to $500 \mu \mathrm{l}$ of coupling buffer containing a given amount of ALP (183 units) dissolved in $0.05 \mathrm{M}$ sodium carbonate, $\mathrm{pH}$ 9.5. The reaction was run for $24 \mathrm{~h}$ at $4^{\circ} \mathrm{C}$ under stirring. The reaction mixture was then dialyzed against $0.05 \mathrm{M}$ Tris- $\mathrm{HCl}, \mathrm{pH} 7.4$, and diluted to a final volume of $2.0 \mathrm{ml}$ with the dialysis buffer. The resulting enzyme conjugates were characterized by their residual activities and percentages of inhibitions induced by an excess amount of avidin..$^{6,8,9}$ All conjugates were kept at $4^{\circ} \mathrm{C}$ until the additions of reagents for activity measurements.

\section{Preparation of avidin-riboflavin conjugates}

3-Carboxymethylriboflavin and its $N$-hydroxysuccinimide (NHS)-activated ester were synthesized as reported previously. ${ }^{10}$ Prior to the coupling reaction, $3.43 \mathrm{mg}$ of avidin was dissolved in $3 \mathrm{ml}$ of coupling buffer, $0.1 \mathrm{M}$ bisTris propane, $\mathrm{pH} 6.5$ or $0.05 \mathrm{M}$ sodium carbonate, $\mathrm{pH} 9.5$. In cases of active-site protection, $1 \mathrm{mg}$ of 2 iminobiotin dissolved in $100 \mu \mathrm{l}$ of DMF was added to the avidin solution. The required amount of NHSactivated ester in DMF $(21.3 \mathrm{mg} / \mathrm{ml})$ was added to $500 \mu \mathrm{l}$ of the avidin/iminobiotin solution, and the coupling reaction was run for $24 \mathrm{~h}$ at $4^{\circ} \mathrm{C}$ under stirring. The mixture was then dialyzed against $50 \mathrm{mM}$ ammonium acetate $/ 0.5 \mathrm{M} \mathrm{NaCl}$ buffer, $\mathrm{pH} 4.0$, and diluted to a final volume of $2.0 \mathrm{ml}$ with $0.05 \mathrm{M}$ Tris- $\mathrm{HCl}$ buffer, $\mathrm{pH}$ 7.4. The resulting avidin conjugates were characterized by their ability to inhibit the ALP-biotin activity in the presence or absence of RBP (Table 1) as described below.

\section{Determination of enzymatic activity and percentage inhibi- tion}

The rate of appearance of $p$-nitrophenol, measured by the change in absorbance at $405 \mathrm{~nm}$ per unit time, was used to determine the activity of ALP-biotin conjugates. The assay involves addition of $100 \mu \mathrm{l}$ of $p$-nitrophenyl phosphate $(30 \mathrm{mM})$ and $100 \mu \mathrm{l}$ of an ALP-biotin conjugate to a tube containing $700 \mu$ l of assay buffer. After mixing and agitation $(1-2 s)$ the reaction mixture was aspirated into the thermostated flow cell of the spectrophotometer. The absorbance of the mixture in each tube was read over a $1-\min$ period $(\Delta A / \mathrm{min})$ after an initial 20-s delay. In order to determine the percentage inhibition value for each conjugate, $100 \mu$ l of the assay buffer was replaced by $100 \mu \mathrm{l}$ of avidin or avidin-riboflavin $(0.3 \mathrm{mg} / \mathrm{ml})$ prepared in assay buffer. In addition, the conjugates were first incubated with avidin or avidin-riboflavin for $10 \mathrm{~min}$ before subsequent addition of substrate solutions. The reversed percentage inhibition was determined by incubating $100 \mu \mathrm{l}$ of each avidin-riboflavin conjugate $(0.3 \mathrm{mg} / \mathrm{ml})$ with $100 \mu \mathrm{l}$ of RBP $(1 \mathrm{mg} / \mathrm{ml})$ for $15 \mathrm{~min}$, adding $100 \mu \mathrm{l}$ of an ALP-biotin conjugate (1:100 dilution; 0.09 units/ $\mathrm{ml}$ ), and incubating the mixture for $10 \mathrm{~min}$.

\section{Dose-response curves}

For dose-response curves for RBP, $100 \mu$ of solutions containing different amounts of RBP was incubated with $100 \mu \mathrm{l}$ of a diluted avidin conjugate and $500 \mu \mathrm{l}$ of assay buffer for $15 \mathrm{~min}$. After $100 \mu \mathrm{l}$ of a diluted ALP conjugate was added, the mixture was incubated for $10 \mathrm{~min}$, and the resulting enzymatic activity was measured. For riboflavin dose-response curves, $100 \mu \mathrm{l}$ of the riboflavin standards were added to an assay tube containing $100 \mu \mathrm{l}$ of an RBP solution and $400 \mu$ l of assay buffer. After incubation for $10 \mathrm{~min}, 100 \mu \mathrm{l}$ of an avidin conjugate (Avidin-RF7 in Table 1) was added, and the mixture was incubated for a further 5-min period. A volume of $100 \mu \mathrm{l}$ of an ALP conjugate solution was then added, and the 
Table 1 Characteristics of avidin-riboflavin conjugates

\begin{tabular}{|c|c|c|c|c|}
\hline Conjugate $^{\mathrm{a}}$ & Coupling condition & $\begin{array}{c}\text { Initial ratio } \\
\text { (riboflavin/avidin) }\end{array}$ & $\begin{array}{c}\% \text { Inhibition }^{\mathrm{b}} \\
\text { (without RBP) }\end{array}$ & $\begin{array}{l}\text { \% Inhibition }{ }^{\mathrm{c}} \\
\text { (with RBP) }\end{array}$ \\
\hline Avidin-RF 1 & & 20 & 75 & 34 \\
\hline Avidin-RF 2 & pH 6.5 & 40 & 70 & 21 \\
\hline Avidin-RF 3 & without iminobiotin & 60 & 66 & 8 \\
\hline Avidin-RF 4 & & 80 & 54 & 0 \\
\hline Avidin-RF 5 & & 20 & 76 & 32 \\
\hline Avidin-RF 6 & pH 6.5 & 40 & 71 & 14 \\
\hline Avidin-RF 7 & with iminobiotin & 60 & 69 & 6 \\
\hline Avidin-RF 8 & & 80 & 57 & 0 \\
\hline Avidin-RF 9 & & 20 & 69 & 42 \\
\hline Avidin-RF 10 & pH 9.5 & 40 & 66 & 41 \\
\hline Avidin-RF 11 & without iminobiotin & 60 & 63 & 38 \\
\hline Avidin-RF 12 & & 80 & 61 & 19 \\
\hline Avidin-RF 13 & & 20 & 71 & 38 \\
\hline Avidin-RF 14 & pH 9.5 & 40 & 68 & 36 \\
\hline Avidin-RF 15 & with iminobiotin & 60 & 67 & 33 \\
\hline Avidin-RF 16 & & 80 & 64 & 25 \\
\hline
\end{tabular}

a. Avidin-RF: avidin-riboflavin. b. Percentage inhibition was determined by using $1: 100$ dilutions of ALPbiotin 3 and $0.03 \mathrm{mg}$ of each avidin-RF conjugate. c. Reversed percentage inhibition was determined by using $0.1 \mathrm{mg}$ of RBP.

mixture was incubated for $10 \mathrm{~min}$ prior to activity measurements.

\section{Results and Discussion}

Since the analytical signal of the homogeneous type assay results from inhibition of conjugate catalytic activity, a highly inhibited enzyme conjugate is required for the sensitive assay development. Thus, the choice of labeling enzyme is more restricted for the homogeneous assay than for the heterogeneous assay. Indeed, types of enzymes employed in the EMIT type homogeneous methods have been limited only to several two-substrate enzymatic systems..$^{1-3}$ For the biotin-avidin mediated homogeneous methods, however, the label can be selected from a wide range of enzymes including singlesubstrate adenosine deaminase and ALP, as demonstrated in our previous work. ${ }^{6}$

In the present work, four different ALP-biotin conjugates were newly synthesized by employing relatively high initial molar NHS-biotin/ALP ratios (i.e., 1500, 1750,2000 , and 2250) during the conjugation reaction. All of these conjugates retained relatively high residual activities (i.e., $40-47 \%$ of the unconjugated ALP activity), and were inhibited to a great extent (i.e., 77 $86 \%$ ) by excess avidin. As expected, a higher initial biotin/enzyme ratio yielded a greater conjugate inhibition, which occurred at the expense of a decrease in the residual activity of the conjugate. The ALP-biotin conjugate prepared by employing an initial molar NHSbiotin/ALP ratio of 2000 (ALP-biotin 3) exhibited the most desired properties, with a residual activity of $42 \%$ and a maximum inhibition of $86 \%$, and thus was used in all subsequent experiments.

The characteristics of the enzyme-linked binding assays is also highly dependent upon the ability of the anti-analyte binder to bind to the enzyme conjugate. In the present biotin-avidin mediated assay method, the binding abilities of avidin-riboflavin to both ALP-biotin and RBP affect the detection capabilities of the method. In order to accomplish a sensitive homogeneous method, the avidin-riboflavin conjugate should possess high binding affinity towards biotin appended to enzyme, and, thus, induce substantial inhibition. In addition, the observed inhibition needs to be reversed when RBP binds riboflavin attached to avidin. In this work, a variety of avidin-riboflavin conjugates were synthesized by varying initial molar riboflavin/avidin ratios, and by performing the reaction at two different $\mathrm{pHs}$ (i.e., $\mathrm{pH} 6.5$ and 9.5) with or without active-site protection (see Table 1).

It was thought that active-site protection may be required for the avidin-riboflavin conjugation reaction in order to prevent attachment of riboflavin to the binding sites of avidin. However, biotin cannot be used for this purpose, because of an extremely high affinity of biotin toward avidin $\left(K_{\mathrm{a}}=10^{15} \mathrm{M}^{-1}\right)$ : the binding is undisturbed by extremes of $\mathrm{pH}$, buffer salts or even chaotropic agents (e.g., $3 \mathrm{M}$ guanidine hydrochloride). Therefore, iminobiotin, a biotin derivative which has a much lower affinity toward avidin $\left(K_{\mathrm{a}}=10^{7} \mathrm{M}^{-1}\right)^{11}$, was employed for the purpose of protecting the binding sites of avidin. However, the interaction of 2-iminobiotin with avidin is tight at high $\mathrm{pH}(>9)$ and becomes increasingly weaker as the $\mathrm{pH}$ is lowered. For instance, at $\mathrm{pH} \mathrm{6,} \mathrm{about} \mathrm{half} \mathrm{of}$ the stoichiometrically added 2-iminobiotin molecules are bound to avidin, as indicated previously by a spectral shift titration experiment. ${ }^{12}$ In the present work, a 80- 
fold excess of 2-iminobiotin to avidin was employed for the avidin-riboflavin conjugation reaction at $\mathrm{pH} 6.5$ and 9.5. Such an excess of 2-iminobiotin was thought to be more than adequate for active-site protection. Since dissociation of the avidin-iminobiotin complex occurs at $\mathrm{pH} 4^{11,12}$, iminobiotin was removed by dialysis at $\mathrm{pH} 4$ after the avidin-riboflavin conjugation reaction.

Table 1 summarizes the characteristics of various avidin-riboflavin conjugates prepared in this work. As can be seen, in all cases, the ability of the avidinriboflavin conjugate to inhibit the enzyme-biotin conjugate decreases, as the initial molar ratio of riboflavin/ avidin (thus, the degree of substitution) increases during the coupling reaction. However, the reversed extent of the observed inhibition by a given excess of RBP (the last column of Table 1) increases as the degree of substitution increases. This can be explained by a statistical effect due to an increased number of riboflavins attached to avidin. $^{6}$ In this experiment, a better conjugate resulted from the reaction with active-site protection. In Table 1 , for example, avidin-RF2 prepared at $\mathrm{pH} 6.5$ without active-site protection possesses an inhibitory property similar to those of avidin-RF6 or avidin-RF7. However, avidin-RF6 or -RF7, prepared with active-site protection, reverses the observed inhibition to a greater extent by a given amount of RBP (this tendency is also observed at $\mathrm{pH}$ 9.5). On the other hand, the conjugate properties were found to be better at $\mathrm{pH} 6.5$ (compare avidin-RF 2 and avidin-RF13 having a similar inhibitory property of $71 \%$ ). Of the conjugates prepared, avidinRF7 was chosen for use as the signal modulator in subsequent experiments.

Association kinetics of avidin-riboflavin with ALPbiotin and RBP were examined. Information on both reactions is needed to determine optimal incubation periods for the assay. Figure 1 illustrates the effects of changing the reaction time on the percentage inhibition of the ALP conjugate induced by avidin-riboflavin and on the percentage reversal of the observed inhibition by RBP. As can be seen, $>95 \%$ of the maximum value was achieved within $5 \mathrm{~min}$ for inhibition and within $13 \mathrm{~min}$ for reversal, respectively. In this study, the rate of association between avidin-riboflavin and RBP was measured in a sequential binding mode ${ }^{13}$ by first reacting avidin-riboflavin with RBP for a given incubation period and then adding ALP-biotin and substrates. It was assumed that this type of assay protocol enhances the binding capability of avidin-riboflavin toward RBP over enzyme-biotin, and, thus, a smaller amount of RBP can be used to achieve the same extent of RBP-induced reversal (i.e., analytical signal), resulting in an assay with a better detection capability. In subsequent experiments, incubation periods of $15 \mathrm{~min}$ (avidin-riboflavin/ RBP) and $10 \mathrm{~min}$ (avidin-riboflavin/RBP/ALP-biotin) were selected to gain a nearly maximum change in signal for the method.

Three dose-response curves for RBP were constructed by using three different combinations of the ALP-biotin and avidin-riboflavin concentrations in the assay mix-

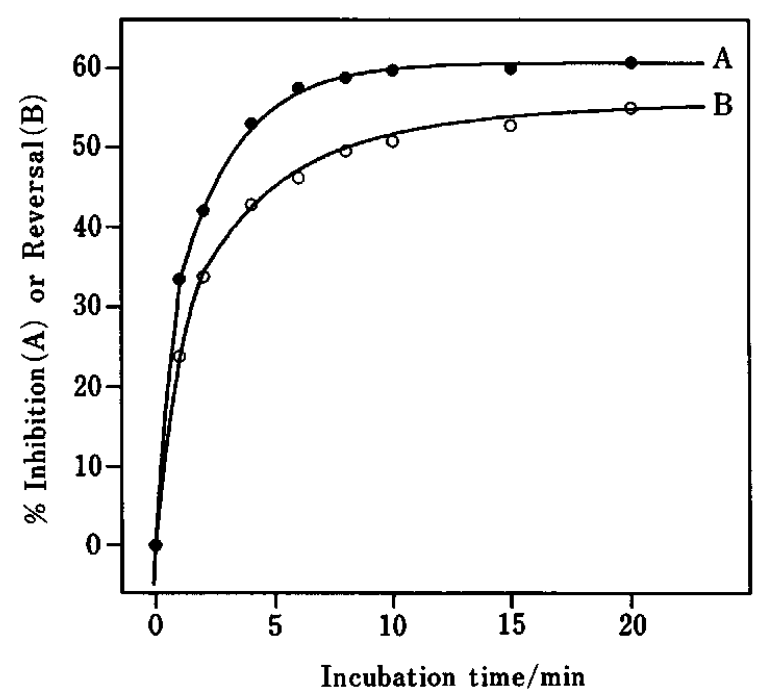

Fig. 1 Effects of varying the incubation time (A) on the percentage inhibition of the ALP conjugate induced by avidin and (B) on the percentage reversal of the observed inhibition by RBP. ALP-biotin ( 0.09 units) and avidin-RF7 $(0.3 \mathrm{mg})$ were employed with $0.1 \mathrm{mg}$ of RBP. Values shown are an average of duplicate measurements.

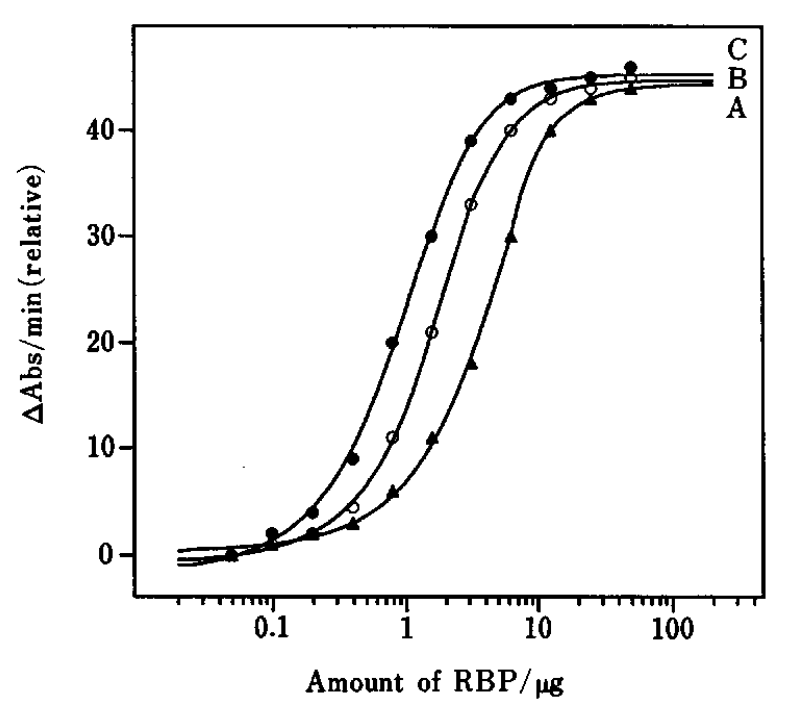

Fig. 2 Effects of varying ALP-biotin and avidin-riboflavin concentrations on the dose response curve for RBP: (A) 0.06 units of ALP-biotin and $3.6 \mu \mathrm{g}$ of avidin-riboflavin; (B) 0.09 units of ALP-biotin and $1.8 \mu \mathrm{g}$ of avidin-riboflavin; and (C) 0.12 units of ALP-biotin and $0.44 \mu \mathrm{g}$ of avidin-riboflavin. Avidin-RF7 in Table 1 is used and values shown are an average of duplicate measurements.

ture. As shown in Fig. 2, increasing the amount of the ALP conjugate while decreasing the amount of the avidin conjugate results in a curve with a lower detection capability. However, this comes at the expense of an increase in the signal-to-noise ratio caused by an increased level of the background enzymatic signal (i.e., a 
greater amount of ALP conjugate present in the assay tube). All of the curves are relatively steep over a narrow concentration range, indicating that the assay can be used for the sensitive determination of RBP. The amount of RBP needed to regain $>95 \%$ of the initial activity of the added ALP conjugate is $12.5 \mu \mathrm{g}$ with curve A, $6.3 \mu \mathrm{g}$ with curve B and $3.1 \mu \mathrm{g}$ with curve C.

Finally, competitive dose-response curves for riboflavin were constructed by employing three different ratios of avidin-riboflavin/RBP with a fixed amount of the ALP-biotin conjugate (Fig. 3). It is known that the characteristics (i.e., detection limit, effective detection range, and steepness) of the EMIT type dose-response curve are affected by the ratio of binder/enzyme conjugate employed in the assay mixture and the affinity constants of the binder for both the free analyte and the conjugate..$^{8,14,15}$ The theoretical treatment for the present method involving two different binding reactions is much more complicated than that for the conventional EMIT method. It can be seen from Fig. 3, however, that a different reagent ratio in the assay mixture results in different dose-response behavior: a conjugate with a higher avidin-riboflavin/RBP ratio yielded a steeper curve with a higher detection limit.

Factors that determine the detection capabilities of the enzyme-linked competitive binding assays are manifold: detectability and degree of ligand substitution in the enzyme-ligand conjugates utilized, binding capability of the binder systems involved, etc. However, in the present biotin-avidin mediated method involving two different binder systems (i.e., avidin-biotin and target analyte binder systems), the detectability of the assay system is affected mainly by the target analyte binder system, since the association of the avidin-biotin system is extremely strong. Thus, we believe that the detection capability of the proposed biotin-avidin mediated assay system is a function of the analyte system chosen and of our ability to optimize the assay conditions, just as is the case of the conventional EMIT type assays.

In summary, the feasibility of using a single-substrate ALP as a generic label in homogeneous type assays has been demonstrated by employing the biotin-avidin mediated assay protocol with riboflavin and RBP as the model analyte system. Work on further demonstrating the practical applicability of the ALP-based assay (i.e., real sample studies) is currently in progress as are efforts to adapt the proposed assay system to other analyte systems.

This work was supported by the Ministry of Education, Korea, through the Basic Science Research Institute Program (BSRI-95-3405).

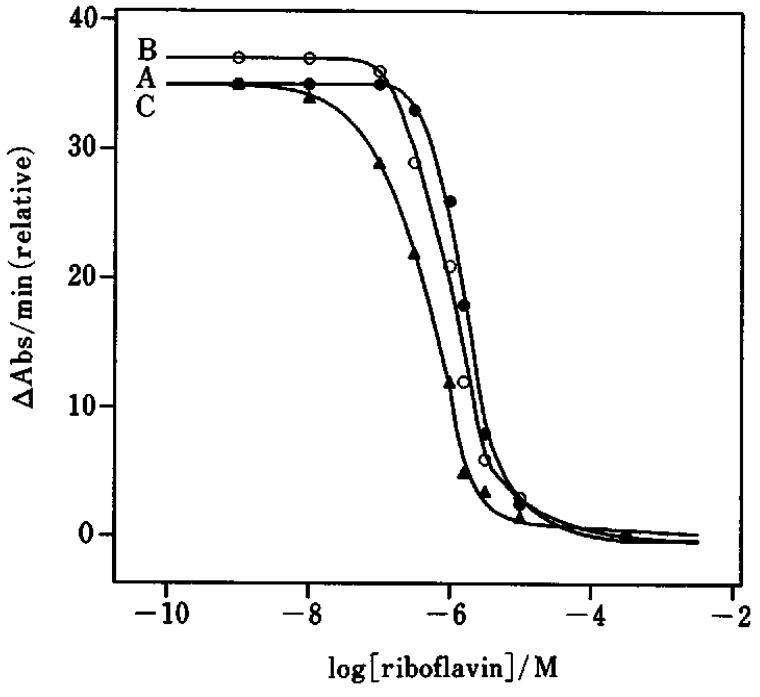

Fig. 3 Effect of varying avidin-riboflavin and RBP concentrations on the dose response curve for riboflavin: (A) $3.6 \mu \mathrm{g}$ of avidin-riboflavin and $1.6 \mu \mathrm{g}$ of RBP; (B) $1.8 \mu \mathrm{g}$ of avidin-riboflavin and $6.25 \mu \mathrm{g}$ of RBP; and (C) $0.44 \mu \mathrm{g}$ of avidin-riboflavin and $12.5 \mu \mathrm{g}$ of RBP. Avidin-RF7 in Table 1 is used with a fixed amount of ALP-biotin (0.09 units), and values shown are an average of duplicate measurements.

2. A. Voller and D. E. Bidwell, in "Alternative Immunoassay", ed. W. P. Collins, p. 77, Wiley, New York, 1985.

3. E. F. Ullman and E. T. Maggio, in "EnzymeImmunoassay", ed. E. T. Maggio, p. 105, CRC Press, Boca Raton, 1980.

4. K. E. Rubenstein, R. S. Schneider and E. F. Ullman, Biochem. Biophys. Res. Commun., 47, 846 (1972).

5. G. L. Rowley, K. E. Rubenstein, J. Huisjen and E. F. Ullman, J. Biol. Chem., 250, 3759 (1975).

6. M. J. Kim, H. J. Kim, J. M. Kim, B. Kim, S. H. Han and G. S. Cha, Anal. Biochem., 231, in press (1995).

7. B. Kim, J. M. Buckwalter and M. E. Meyerhoff, Anal. Biochem., 218, 14 (1994).

8. T. L. Kjellstrom and L. G. Bachas, Anal. Chem., 61, 1728 (1989).

9. S. S. Daunert, L. G. Bachas and M. E. Meyerhoff, Anal. Chim. Acta, 208, 43 (1988).

10. G. S. Cha and M. E. Meyerhoff, Anal. Biochem., 168, 216 (1988).

11. R. Zeheb, V. Chang and G. A. Orr, Anal. Biochem., 129, 156 (1983).

12. G. A. Orr, J. Biol. Chem., 256, 761 (1981).

13. A. Zettner and P. E. Duly, Clin. Chem., 20, 5 (1974).

14. G. S. Cha and M. E. Meyerhoff, Anal. Chim. Acta, 208, 31 (1988).

15. L. G. Bachas and M. E. Meyerhoff, Anal. Biochem., 156, 223 (1986). 